\title{
Uusia keinoja maatalouskosteikkojen toiminnan tehostamiseen
}

\author{
Tulonen Piia, Stenman Tarja \\ Jyväskylän ammattikorkeakoulu, Tuumalantie 17, 43130 Tarvaala \\ tulonenpiia@gmail.com,tarja.stenman@jamk.fi
}

\section{TIIVISTELMÄ}

Ilmastonmuutoksen myötä kosteikkojen merkitys vesiensuojelussa, tulvien torjunnassa sekä myös kasteluveden varastona kasvaa. Talvikauden aikaisen maa-alueilta peräisin olevan ravinne- ja kiintoainehuuhtouman ennakoidaan kasvavan. Kosteikkojen vesiensuojelulliset toimintamekanismit sedimentaatio, denitrifikaatio, adsorptio ja ravinteiden kertyminen biomassaan - tunnetaan hyvin, mutta myös uutta tutkimustietoa toimintamekanismien tehostamisesta on saatu. Tehokkuuteen vaikuttavista toimista tärkeimmiksi nousevat kosteikon riittävä koko, tarkoin valittu sijainti sekä kosteikon hoito. Kosteikon toimintaa voidaan tehostaa kasvilajivalinnoilla. Jo suunnitteluvaiheessa voidaan valita vesiensuojelullisesti tehokkaita kasvilajeja, joita kosteikolle istutetaan. Mahdollisesti myös puumateriaalin hyödyntämisellä voidaan tehostaa kosteikon toimintaa. Jyväskylän ammattikorkeakoulun Biotalousinstituutin agrologiopiskelija Piia Tulonen selvitti opinnäytetyössään maatalouden vesiensuojelukosteikkojen toiminnan tehostamiskeinoja.

Asiasanat: vesiensuojelu, maatalouskosteikot, kosteikkokasvillisuus

\section{Johdanto}

Ilmastonmuutoksen myötä Suomessa keskilämpötila kasvaa, talvet leutonevat, talviaikainen sadanta lisääntyy ja talven lumikuorma pienenee. Tämän seurauksena kevään tulvapiikit, jotka tulevat usein pintavaluntana, vähenevät, kun taas pohjavalunta kasvaa ja kasvinsuojeluaineita, ravinteita sekä kiintoainesta huuhtoutuu pelloilta entistä enemmän. Suomi on sitoutunut pitämään vesiensä ekologisen tilan vähintään hyvänä. Kosteikot nähdään yhtenä tärkeänä vesiensuojelukeinona tämän tavoitteen saavuttamiseksi (SYKE 2007, Puustinen ym. 2010).

Maatalous on edelleen Suomessa merkittävin vesien rehevöittäjä. Maatalouskosteikoiden ensisijainen tehtävä on puhdistaa valumavesiä, mutta niillä nähdään olevan muitakin hyötyjä, kuten niiden vaikutus luonnon- ja maiseman monimuotoisuuteen, kasteluvesien varastointiin, tulvapiikkien tasaamiseen ja riista- ja virkistyskäyttöön (SYKE 2015). Kosteikon valumavettä puhdistavat mekanismit tunnetaan Suomessa hyvin. Uutta tutkimustietoa kosteikkoalalta on saatu ja uutta tutkimusta tehdään parhaillaan. Luonnonvarakeskus (Luke) on tutkinut kasvilajien ja biohiilen merkitystä kosteikolla ja Suomen ympäristökeskuksessa (SYKE) on käynnissä hanke, jossa selvitetään puuaineksen vaikutusta vesienpuhdistukseen kosteikolla.

Tässä opinnäytetyössä oli tarkoituksena selvittää, miten kosteikoiden vesiensuojelullista tehokkuutta voidaan parantaa. Tuloksena syntyi teos, joka sisältää vanhan, mutta edelleen ajantasaisen, ja uuden tiedon kosteikon toiminnasta, toiminnan tehostamisesta sekä kosteikon hoitotoimista.

\section{Materiaali ja menetelmät}

Tutkimus suoritettiin teoreettisena, kvalitatiiviseen eli laadulliseen tutkimusmenetelmään perustuen. Aineistona käytettiin eri kirjallisuuslähteitä, kuten aiempia tutkimuksia sekä Suomesta että maailmalta, oppaita kosteikkojen perustamiseen ja hoitoon sekä eri ympäristötahojen julkaisuja ja verkkosivuja. Muutamat lähteet koskien kosteikkojen toimintamekanismeja ovat yli 15 vuotta vanhoja, mutta niiden tieto on edelleen ajantasainen. Tuoreemmissa lähteissä käsiteltiin mm. kosteikon kasvillisuutta sekä puumateriaalin ja biohiilen käyttöä. 


\section{Tulokset}

\section{Kosteikon toimintamekanismit}

Kosteikon valumavesien laatuun vaikuttavat mekanismit ovat sedimentaatio, denitrifikaatio, adsorptio sekä ravinteiden kertyminen biomassaan. Sedimentaatiolla on vaikutusta kiintoaineksen ja sitä kautta myös fosforin pidättymiseen kosteikolla, koska fosfori on usein kiinnittyneenä kiintoainekseen.

Denitrifikaatiossa bakteeritoiminnan myötä typpi muuttuu kaasuksi ja pidättyy sitä kautta kosteikolla. Adsorptiossa vedessä liuenneessa muodossa oleva fosfori pidättyy sedimenttiin. Ravinteiden kertyminen biomassaan tarkoittaa kasvien kykyä ottaa vedestä ja maaperästä ravinteita kasvuunsa. (Puustinen ym. 2000, Puustinen ym. 2007).

Sedimentaatio vaatii pitkän vedenviipymän ja hitaan vedenvirtauksen, jotta kiintoaines ehtii laskeutua kosteikon pohjalle. Kasvillisuus osaltaan hidastaa vedenvirtausta. Mitä pienemmän partikkelikoon kiintoainesta kosteikolle tulee, sitä pidempi vedenviipymä tulisi kosteikolle saada. Esimerkiksi savi on erittäin hienoa eikä siten helposti vajoa kosteikon pohjalle (Puustinen ym. 2000).

Denitrifikaatio vaatii hapettomia oloja ja orgaanista-ainesta. Denitrifikaatiobakteerit käyttävät happea hajottaessaan orgaanista-ainesta. Jos happea on suoraan vedestä saatavilla, bakteerit käyttävät sen eikä denitrifikaatiota tapahdu. Hapettomissa oloissa bakteerit ottavat hapen saatavilla olevasta nitraattitypestä, jolloin denitrifikaatio pääsee tapahtumaan eli kaasuuntunut typpi haihtuu kosteikolta. Bakteerien aktiivisuudella, syvyysvaihtelulla ja kasvillisuudella (orgaaninen aines) on merkitystä denitrifikaation tehokkuuteen. Bakteerit ovat aktiivisempia lämpimämmissä oloissa $\left(0-30{ }^{\circ} \mathrm{C}\right)$, mikä tarkoittaa sitä, että denitrifikaatio kärsii Suomessa etenkin talviaikana. (Puustinen ym. 2000, Puustinen ym. 2007).

Adsorptio, jossa vedessä liuenneessa muodossa oleva fosfori (DRP, dissolved reactive phosphorus) pidättyy sedimenttiin, tapahtuu vain, jos valuma-alueelta tulevan veden DRP on korkeampi kuin kosteikon maa-aineksen (Kuva 1). Mikäli DRP kosteikon maa-aineksessa on valumavettä korkeampi, fosforia vapautuu kosteikolla eli tapahtuu ns. resorptio (Puustinen ym. 2007).

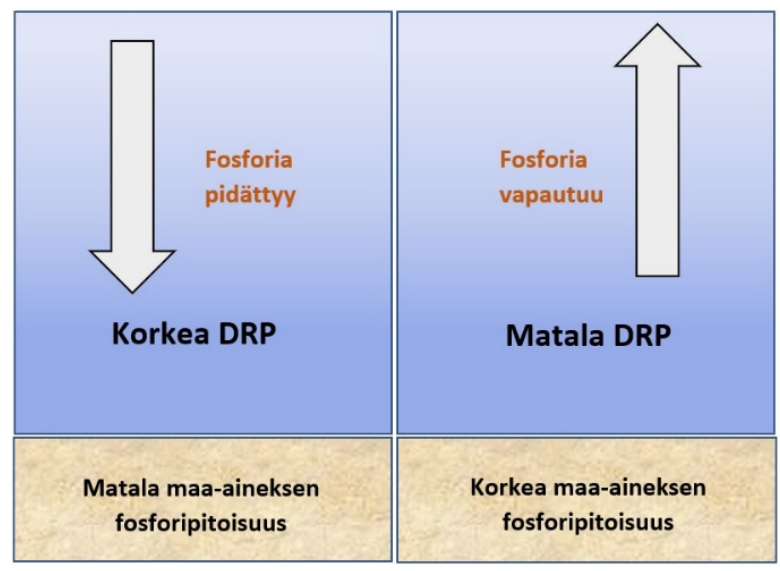

Kuva 1. Kuvassa havainnollistetaan adsorptio. Jos kosteikolle tulevan valumaveden DRP (dissolved reactive phosphorus) eli vedessä liuenneessa muodossa olevan fosforin pitoisuus on korkeampi kuin kosteikon maaaineksen, fosforia pidättyy kosteikolla.

Adsorptio vaatii vapaata, fosforilla kyllästymätöntä rautaa. Nämä varannot aikanaan loppuvat kosteikolta, jolloin adsorption teho heikkenee (Puustinen ym. 2007).

Kasvit käyttävät ravinteita kasvuunsa ja yhteyttämiseen. Kasveja kasvaa kosteikolla eri kerroksissa (Kuva 2). Kasvillisuuden ollessa runsasta ja kerroksellista, on ravinteiden pidättyminen suoraan biomassaan tehokkaampaa (Puustinen ym. 2000). 


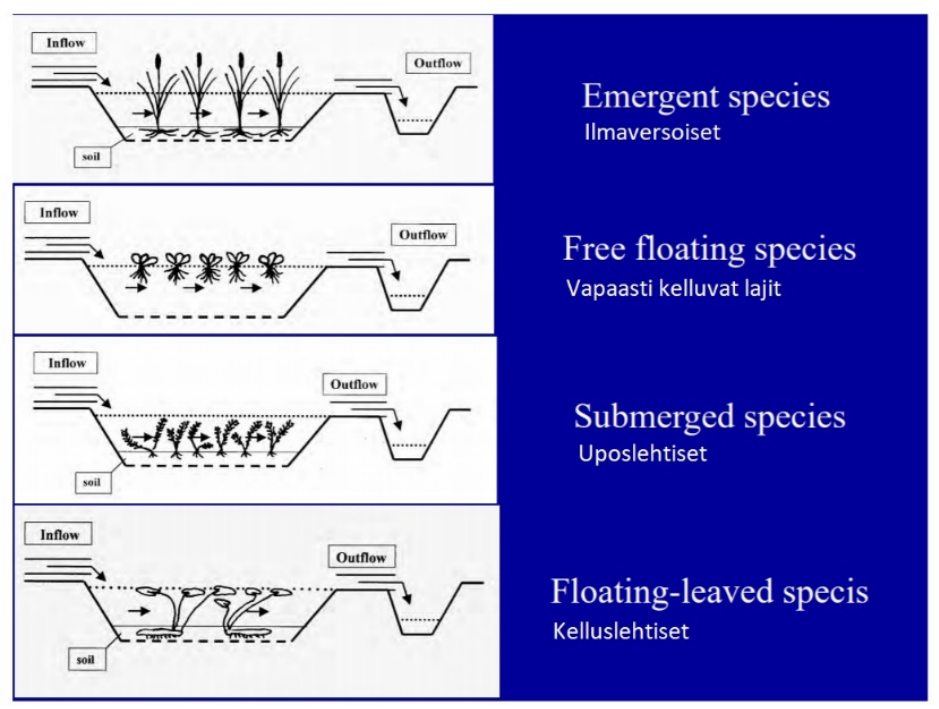

Kuva 2. Kasvien eri kasvukerrokset vesiympäristössä. Huolehtimalla kosteikon kerroksellisesta ja runsaasta kasvillisuudesta, voidaan edistää tehokasta ravinteiden kertymistä kasvien biomassaan. (Vymazal n.d.)

\section{Kosteikon toimintaedellytykset}

Edellä mainittujen kosteikon toimintamekanismien tehokkuuteen vaikuttavat muun muassa kosteikon koko ja sijainti sekä valuma-alueen ja kosteikon ominaisuudet sekä lämpötila. Hyvällä suunnittelulla ja sijoittamisella luodaan edellytykset tehokkaalle ravinteiden pidättymiselle kosteikolla.

Mitä suurempi kosteikko on suhteessa valuma-alueen kokoon ja mitä pidempi vedenviipymä saavutetaan, sitä enemmän kosteikko pystyy pidättämään ravinteita (Kuva 3). Vesiensuojelullisen tehokkuuden varmistamiseksi kosteikon tulisi olla vähintään $1 \%$ valuma-alueen koosta. Suositeltu yhden vuorokauden vedenviipymä saavutetaan, kun kosteikon koko valuma-alueesta on yli $2 \%$. (Puustinen ym. 2000, Puustinen ym. 2001).

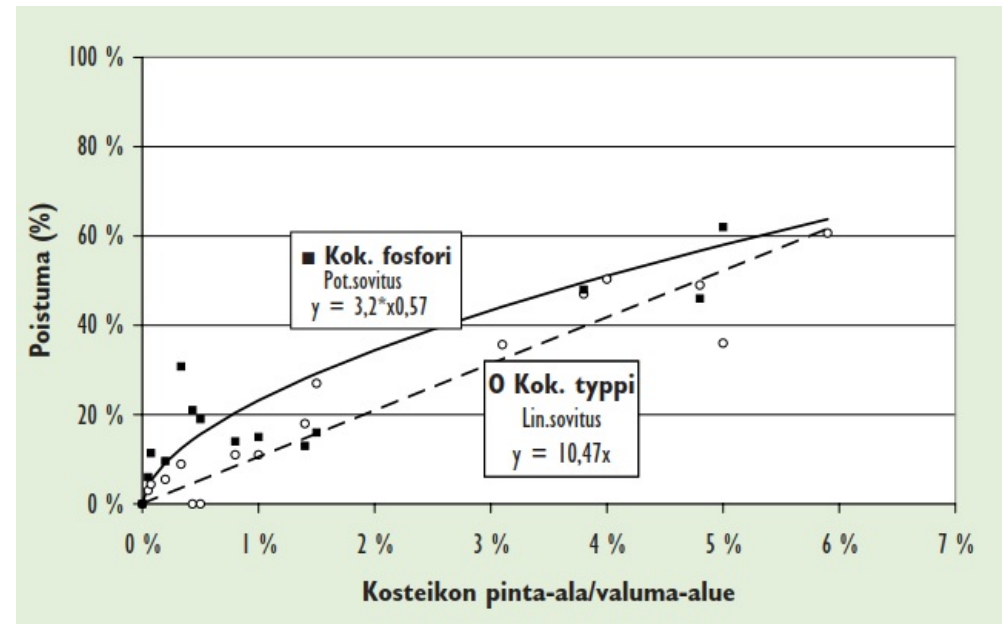

Kuva 3. Kosteikon kyky pidättää fosforia ja typpeä tehostuu sitä mukaan, mitä suurempi kosteikko on sen valuma-alueeseen nähden. Kuvassa on pohjoismaisissa ja yhdysvaltalaisissa kosteikoissa mitattuja kokonaisfosfori- ja kokonaistyppipoistumia suhteessa kosteikkojen pinta-ala/valuma-alue suhteisiin (Puustinen ym. 2007).

Kosteikon sijoittamisessa tulee huomioida valuma-alueen sekä kosteikon ominaisuudet. Yleisesti ohjeena on, että valuma-alueen pinta-alasta tulisi vähintään $10 \%$ olla peltoa, jotta kosteikko kannattaa perustaa. Kosteikko toimii sitä tehokkaammin, mitä ravinteikkaampaa vettä sinne tulee ja esimerkiksi adsorption toiminta varmistetaan sillä, että valuma-alueelta tulee riittävästi fosforia. Jos valuma-alueen 
maaperä on savipitoista, tulisi kosteikko suunnitella siten, että vedenviipymä saadaan mahdollisimman pitkäksi, sillä saven sedimentoituminen on hidasta. Mikäli valuma-alueen maaperä on suurempaa partikkelikokoa, riittää kosteikolla lyhyempi viipymä. Toisaalta valuma-alueen kaltevuussuhteet vaikuttavat myös kiintoaineksen määrään, sillä suurempi virtausnopeus vaikuttaa eroosioon voimakkaammin (Puustinen ym. 2000, Puustinen ym. 2001).

Kosteikon ominaisuuksilla on myös merkitystä kosteikon toimintaan. Matala DRP-pitoisuus kosteikon maa-aineksessa ja orgaanisen aineen määrä kosteikolla tehostavat kosteikon toimintamekanismeja. Koska denitrifikaatio ja adsorptio vaativat erilaiset olosuhteet, tulee varmistaa, että kosteikosta tulee mosaiikkimainen, sen syvyysolosuhteet vaihtelevat ja kasvillisuus on kerroksellista ja runsasta. Nämä voidaan huomioida kosteikon suunnitteluvaiheessa.

\section{Kasvillisuus kosteikolla}

Kasvillisuus vaikuttaa kosteikolla monella eri tavalla. Sen lisäksi, että se kerryttää ravinteita suoraan biomassaansa, se myös stabiloi maaperää vähentäen eroosio- ja resuspensioriskiä, hidastaa veden virtausta sekä suodattaa kiintoainesta kasvillisuuden kautta. Lisäksi veteen liuennutta fosforia assimiloituu kasvillisuuden pintaan ja kasvillisuus tuottaa happea sedimenttiin ja veteen. Kasvillisuus toimii myös kasvualustana denitrifikaatiobakteereille. Yhdessä lumipeitteen kanssa kasvillisuus suojaa kosteikkoa kokonaisvaltaiselta jäätymiseltä talvella (Puustinen ym. 2001).

Kasvin kyky käyttää ravinteita ja vettä, juuriston laajuus ja tiheys, kasvillisuuden tiheys sekä kerroksellisuus vaikuttavat siihen, millainen merkitys eri kasvilajeilla on kosteikon valumaveden laatuun. Koska kosteikoilla usein tavoitellaan vesiensuojelun lisäksi myös esimerkiksi luonnon monimuotoisuutta parantavia ominaispiirteitä, kannattaa huomio kiinnittää mahdollisimman monimuotoiseen kasvillisuuteen. Pajut, osmankäämi, järviruoko, haarapalpakko ja korpikaisla ovat tehokkaita kasveja kosteikolla, mutta ne ovat myös voimakkaasti leviäviä ja saattavat jättää vaateliaammat kasvit alleen. Tästä syystä näitä kasveja kannattaa suosia kosteikolla varauksella (Juhanoja ja Tuhkanen 2019).

Kasvillisuuden kehittymiseen kosteikolle vaikuttavat mahdolliset kasvillisuuden perustamistoimet sekä kosteikon sijainti. Kasvillisuuden voi joko istuttaa, viljellä tai antaa luontaisesti kehittyä. Maatalouskosteikon perustaja on usein yksityinen tilallinen, joka budjettia säästääkseen antaa kosteikon kasvittua luontaisesti. Tällöin ei päästä vaikuttamaan kasvillisuuden syntyyn. Kasvillisuus syntyy melko nopeasti, mutta kuitenkin istutusta hitaammin. Ennen kasvillisuuden levittäytymistä, on kosteikkoalue alttiimpi eroosiolle. Kaupunkialueelle perustetulle hulevesikosteikolle kasvillisuus usein istutetaan. Tällöin kosteikon rakenteet saavat eroosiolta suojaavan kasvillisuuden nopeammin ja kasvillisuus saadaan juuri niin monimuotoiseksi kuin halutaan. Istuttamisen ja luontaisen kasvittumisen välimuotona on viljely, jossa haluttujen kasvien siemeniä viljellään kosteikolle (Juhanoja ja Tuhkanen 2019).

Tavanomaisia maatalouskosteikoilla viihtyviä kasveja ovat mm. ratamosarpio, järviruoko, leveäosmankäämi, järvikaisla, ahvenvita, uistinvita, ulpukka, kurjenmiekka, rantakukka, vehka yms. (Puustinen ym. 2007). Hulevesikosteikolla kasvillisuus on pääpiirteissään samantyylinen, mutta hieman monimuotoisempi.

Luken hankkeen Hulevesien kasvit ja kasvualustat (Juhanoja ja Tuhkanen 2019) mukaan kasvit, joilla on voimakas ja laaja juuristo, käyttävät hyvin ravinteita ja haihduttavat vettä tehokkaasti ja ovat siten parhaita kasveja vaikuttamaan valumaveden laatuun ja määrään. Hankkeen astiakokeen tuloksena havaittiin, että tällaisia kasveja ovat mm. viiltosara, korpikaisla, rantatyräkki ja jänönsara.

\section{Biohiilen hyödyntäminen kosteikolla}

Luken hankkeessa Hulevesien kasvit ja kasvualustat (Juhanoja ja Tuhkanen 2019) tutkittiin eri kasvilajien ohella myös biohiilen vaikutusta kosteikolla. Biohiili on maanparannusaine, joka sitoo vettä, ravinteita ja haitta-aineita, parantaa maan huokoisuutta ja ilmanvaihtoa sekä vähentää pintamaan liettymistä. Luken hankkeen astiakokeessa biohiiltä (valmistettu koivusta) oli sekoitettuna kasvualustaan. Biohiili vaikutti kasvien kasvukykyyn ensimmäisenä vuotena negatiivisesti, sillä sen imukyky vei ravinteita kasvien saatavilta. Seuraavina vuosina biohiilen negatiivinen vaikutus tasaantui 
ja biohiili piti kasvualustat kosteampina. Astiakokeessa havaittiin, että biohiilellä oli vaikutusta valumaveden laatuun (Juhanoja ja Tuhkanen 2019).

Biohiilen vaikutusta veden laatuun on tutkittu myös pelto-ojissa. Itä-Suomen yliopistossa selvitettiin, miten biohiili pidättää ravinteita ja haitta-aineita pelto-ojista sekä toimii osana ravinteiden kierrätystä. Tutkimuksessa pelto-ojiin upotettiin biohiiltä, joka sitoi ojan vedestä ravinteita, jonka jälkeen biohiili nostettiin pois ojasta ja hyödynnettiin viereisillä pelloilla maanparannusaineena, jolloin myös ravinteet saatiin takaisin kiertoon (Leppänen 2015).

\section{Puumateriaalin hyödyntäminen kosteikolla}

Puumateriaali kosteikolla saattaa vaikuttaa vedenlaatuun ainakin kahdella tavalla - osana ravintokiertoa tai toimiessaan kasvualustana denitrifikaatiobakteereille. SYKE tutkii puumateriaalin käyttöä osana metsätalouden vesiensuojelua PuuMaVesi-hankkeessa. Hankkeessa olettamuksena on, että kosteikolle tai muuhun vesiensuojelurakenteeseen upotettu puumateriaali tulee osaksi vesiekosysteemin ravintokiertoa. Puun pinnalla alkaa kasvaa levää, sienirihmastoa ja bakteereja, joita esimerkiksi vesiperhosen toukat käyttävät ravinnokseen. Toukka tulee pedon syödyksi tai kasvettuaan isoksi lentää pois kosteikolta viedessään mukanaan ravinteita. Tämän lisäksi puu toimii pitkäkestoisena hiilivarastona. PuuMaVesi-hanke on parhaillaan käynnissä eikä tutkimustuloksia ole vielä julkaistu (SYKE 2018, Metsä Group 2019).

Minnesotassa tutkitaan puuhakkeen käyttöä kosteikolla. Minnesotan tutkimuksessa olettamuksena on, että puuhake toimii kosteikolla denitrifikaatiobakteerien kasvualustana ja siten parantaa kosteikolla typen pidättymistä. Tutkimuksessa haketta levitetään kosteikon pohjalle noin $800 \mathrm{~m}^{3} \mathrm{ha}^{-1}$. Tutkimustuloksia ei ole vielä julkaistu (AP News 2018).

\section{Kosteikkojen hoito}

Kosteikon vesiensuojelullisen tehokkuuden kannalta tärkeimpiä hoitotoimia ovat rakenteiden kunnossapito ja hoito sekä niittäminen ja ruoppaaminen. Ensimmäisenä vuonna kosteikon perustamisen jälkeen on tarkkailtava erityisesti rakenteiden kestävyyttä, koska maanpinta usein painuu rakentamisen jälkeen. Ennen kasvillisuuden kehittymistä kosteikko on myös alttiimpi eroosiolle. Huomiotavia seikkoja ovat ainakin mahdollinen tarve lisämaalle ja patojen, penkereiden sekä luiskien kestävyys (Puustinen ym. 2007).

Niittäminen on tärkeä hoitotoimi, joka tulisi tehdä 1-2 vuoden välein. Niittojäte tulee ehdottomasti poistaa kosteikolta. Tällä varmistetaan, että ravinteet poistuvat kosteikolta. Niittojätteen voi käyttää pelloilla maanparannusaineena. Erään tutkimuksen (Verhofstad ym. 2017) mukaan niittäminen, joka on tehty 2-3 kertaa kasvukaudessa, on tehokkain tapa ravinteiden poistumisen kannalta. Tätä ei Suomessa voida toteuttaa kasvukauden lyhyyden ja lintujen pesimärauhan takaamisen vuoksi. Niittäminen ravinteiden poistamisen lisäksi estää umpeenkasvua, estää kasvillisuuden yksipuolistumista, lisää kasvillisuuden ravinteiden nettopidätyskykyä sekä saattaa vaikuttaa positiivisesti mikrobien runsauteen. (Puustinen ym. 2000, Puustinen ym. 2007, Yang ym. 2016).

Niittoajankohta on valittava tarkkaan ja hyvä ajankohta on usein loppukesä tai alkusyksy, jolloin kasvin sisältämät ravinteet ovat kasvin vihreissä osissa. Jos niittämistä odotetaan liian pitkälle syksyyn, kasvi on siirtänyt ravinteensa juuristoon talvivarastoon. Tällöin niittämisellä tavoiteltu hyöty kärsii. Lisäksi köyhempi ravinnevarasto juuristossa takaa sen, että keväällä, kun kasvi lähtee taas kasvuun se käyttää ravinteita kosteikon vedestä ja pohjasta (Puustinen ym. 2007).

Sedimentaatiossa kosteikon syvänveden altaisiin kertyy ravinteikasta sedimenttiä, joka tulee poistaa säännöllisesti. Sedimenttiä voidaan hyödyntää pelloilla maanparannusaineena. Sedimentin poisto eli ruoppaaminen tulisi tehdä viimeistään siinä vaiheessa, kun altaat alkavat täyttyä sedimentistä. Suositeltu ruoppaustiheys on 2-5 vuoden välein. Jos altaita ei tyhjennetä ajoissa, on vaarana, että suuren valunnan aikana sedimentti lähtee liikkeelle. Ruoppaaminen tulisi tehdä mahdollisimman kuivana ajankohtana, jotta vältytään sedimentin karkaamiselta (Puustinen ym. 2007). 


\section{Tulosten tarkastelu}

Kosteikon valumavesien puhdistustehoon voidaan vaikuttaa suunnittelu- ja rakennusvaiheessa sekä kosteikon hoitotoimilla. Suunnitteluvaiheessa tärkeimpiä tehostamistoimia ovat kosteikon sijoittaminen ja koko. Kosteikkoa ei kannata suunnitella sijoitettavaksi paikkaan, jossa sille ei ole tarvetta. Kosteikko puhdistaa valumavettä sitä tehokkaammin, mitä ravinteikkaampaa vettä sinne tulee. Kosteikon valuma-alueesta peltoa olisi suositeltavaa olla vähintään 10\%. Kosteikon pinta-alan tulisi olla vähintään $1 \%$ valuma-alueen pinta-alasta. Liian pienellä kosteikolla ei saavuteta riittävää veden viipymää. Suunnitteluvaiheessa huomioidaan myös kosteikon rakenne ja muotoilu. Jotta kosteikolle saadaan kaikille toimintamekanismeille (sedimentaatio, adsorptio, denitrifikaatio ja ravinteiden kertyminen biomassaan) toimintaedellytykset, tulee kosteikolla olla syvyysvaihteluja sekä monimuotoinen ja kerroksellinen kasvillisuus sekä oikovirtauksia tulee välttää.

Suunnitteluvaiheessa tulee päättää, annetaanko kasvillisuuden levitä luontaisesti vai onko alueella tarvetta istuttamiselle tai viljelylle. Kasvillisuuden inventointi ennen rakennusvaihetta voi olla hyödyllistä. Inventoinnilla voidaan ennakoida luontaisen kasvillisuuden edellytyksiä kosteikolla. Kasvien istuttaminen lisää kosteikon perustamiskustannuksia ja se onkin monilla maatalouskosteikolla poissuljettu vaihtoehto.

Myöhemmässä vaiheessa kosteikon tehokkuutta voi olla mahdollista lisätä puumateriaalin tai biohiilen avulla. Puumateriaali on usein maatalouskosteikolla helposti saatavilla, varsinkin, jos kohteelta joudutaan raivaamaan puustoa pois. Biohiili ja puumateriaali kosteikolla ovat helppohoitoisia ja vaativat vain vähän hoito- ja huoltotyötä.

Hoitoimet ovat tärkeitä kosteikon toimintaiän sekä toimintavarmuuden pidentämiseksi. Riittävä niittäminen ja ruoppaaminen poistavat ravinteita, estävät umpeenkasvua sekä kasvillisuuden yksipuolistumista, vaikuttavat kasvien nettokasvukykyyn ja mikrobien runsauteen sekä lisäävät virkistyskäyttömahdollisuuksia.

\section{Johtopäätökset}

Maatalouskosteikkojen vesiensuojelulliseen tehokkuuteen voidaan vaikuttaa parhaiten suunnitteluvaiheessa. Erittäin suuri merkitys kosteikon tehokkuuteen on sen sijainnilla ja koolla. Suunnitteluvaiheessa tulee varmistaa, että kosteikko sijoitetaan paikkaan, jossa valuma-alueen pintaalasta vähintään $10 \%$ on peltoa. Mitä ravinteikkaampaa vettä kosteikolle tulee, sen tehokkaammin se toimii. Jotta kosteikon kaikki toimintamekanismit eli sedimentaatio, denitrifikaatio, adsorptio ja ravinteiden kertyminen biomassaan toimisivat riittävällä tasolla, kosteikon on oltava tarpeeksi suuri ja monimuotoinen. Kosteikon tulisi olla kooltaan vähintään $1 \%$ valuma-alueen koosta. Isommalla kosteikolla on lisäksi helpompi saavuttaa monimuotoinen kasvillisuus ja kosteikon mosaiikkimainen ja vaihteleva rakenne. Jotta kosteikko pysyy toimintakykyisenä, vaatii se huoltotyötä. Tämä tarkoittaa kosteikon säännöllistä niittoa ja ruoppaamista. Hoitotoimilla pidennetään kosteikon toimintavarmuutta ja käyttöikää.

Kasvilajivalinnoilla voidaan hieman yrittää vaikuttaa kosteikon tehokkuuteen, mutta maatalouskosteikoiden annetaan kustannussyistä usein kasvittua luontaisesti tai kasvittumista helpotetaan hieman viljelemällä haluttuja kasvinsiemeniä. Tutkimustietoa kasvilajien istuttamisen kustannustehokkuudesta maatalouskosteikoilla ei ole vielä saatavilla. Kustannustehokas keino kosteikon toiminnan tehostamiseen voisi olla puuaineksen lisääminen kosteikolle. Puuta on maaseudulla helposti saatavilla ja tähän käyttötarkoitukseen tarkoitettu puumateriaali on edullista. Puumateriaalin käytöstä kosteikolla ei ole vielä saatu tutkimustuloksia eikä sen käytön kustannustehokkuudesta ole tietoa. 


\section{Kirjallisuus}

Leppänen, M. 2015. Lupaavia tuloksia vesistönsuojelussa: biohiili imee ravinteita ojavesistä. Artikkeli Yleverkkosivuilla. Julkaistu 18.5.2015. Viitattu 17.11.2019. https://yle.fi/uutiset/3-7995899.

Juhanoja, S. \& Tuhkanen, E.-M. 2019. Luonnonkasvit ja biohiili hulevesien hallinnassa. Loppuraportti hankkeesta Hulevesien kasvit ja kasvualustat 2015-2019. Helsinki 2019. Luonnonvara ja biotalouden tutkimus 44/2019.

Metsä Group 2019. Puumavesi-hanke. Esittelyvideo Youtube-sivustolla. Viitattu 20.9.2019. https://www.youtube.com/watch?v=KmQ_vMXkS1M\&feature=youtu.be

AP News 2018. Minnesota watershed uses woodchips, wetlands to treat water. Artikkeli verkkosivulla 1.4.2018. Viitattu 20.9.2019. https://www.apnews.com/b742b6db7906475db4923ed434d95a89.

Puustinen, M., Koskiaho, J., Gran, V., Jormola, J., Maijala, T., Mikkola-Roos, M., Puumala, M., Riihimäki, J., Räty, M. \& Sammalkorpi, I. 2001. Maatalouden vesiensuojelukosteikot. VESIKOT-projektin loppuraportti. Suomen ympäristökeskus julkaisu 499. $12 \mathrm{~s}$.

Puustinen, M., Granlund, K., Salo, T., Siimes, K., Tattari, S., Väisänen, S., Koskiaho, J. \& Linjama, J. 2010. Maatalouden vesiensuojelutoimenpiteiden vaikutukset muuttuvissa ilmasto-oloissa. Suomen Maataloustieteellisen Seuran Tiedote 26. https://doi.org/10.33354/smst.75702

Puustinen, M., Koskiaho, J., Jormola, J., Järvenpää, L., Karhunen, A., Mikkola-Roos, M., Pitkänen, J., Riihimäki, J., Svensberg, M. \& Vikberg, P. 2007. Maatalouden monivaikutteisten kosteikkojen suunnittelu ja mitoitus. Suomen Ympäristö julkaisu 21/2007. Suomen Ympäristökeskus.

Puustinen, M., Koskiaho, J., Puumala, M., Riihimäki, J., Räty, M., Jormola, J., Gran, V., Ekholm, P. \& Maijala, T. 2000. Vesiensuojelukosteikot viljelyalueiden valumavesien hallinnassa. Suomen Ympäristökeskuksen moniste 178 .

SYKE 2007. Vesiensuojelun suuntaviivat vuoteen 2015. Valtioneuvoston periaatepäätös. Suomen Ympäristö julkaisu 10/2007.

SYKE 2015. Monivaikutteiset kosteikot, 2015. Päivitetty 31.12.2015. Viitattu 1.4.2019.

https://www.ymparisto.fi/fi-FI/Vesi/Vesien_kaytto/Maankuivatus_ja_ojitus/Luonnonmukainen_ peruskuivatus/Monivaikutteiset_kosteikot.

SYKE 2018. Puuaines puhdistamaan metsätalouden valumavesiä. Tiedote 18.9.2018. Viitattu 20.9.2019. https://www.syke.fi/fi-FI/Ajankohtaista/Tiedotteet/Puuaines_puhdistamaan_metsatalouden_valu(47904) Vymazal, J. N.d. The Use of Constructed Wetlands for Various Types of Wastewater. Power point -esitys. Viitattu 2.10.2019. https://www.squ.edu.om/Portals/97/Activities/Workshop/WWD2017/CWs-for-variouswastewaters_r1.pdf.

Yang, Z., Wang, Q., Zhang, J., Xie, H. \& Feng, S. 2016. Effect of plant harvesting on the performance of constructed wetlands during summer. Water 2016, 8. https://doi.org/10.3390/w8010024 